$10-1-2013$

\title{
Outdated dermatologic drug samples and obligations to the patient.
}

Jordan Wang

Thomas Jefferson University Hospital

Matthew Keller

Director Psoriasis Center SKMC

Follow this and additional works at: https://jdc.jefferson.edu/dcbfp

Part of the Dermatology Commons

Let us know how access to this document benefits you

\section{Recommended Citation}

Wang, Jordan and Keller, Matthew, "Outdated dermatologic drug samples and obligations to the patient." (2013). Department of Dermatology and Cutaneous Biology Faculty Papers. Paper 50. https://jdc.jefferson.edu/dcbfp/50

This Article is brought to you for free and open access by the Jefferson Digital Commons. The Jefferson Digital Commons is a service of Thomas Jefferson University's Center for Teaching and Learning (CTL). The Commons is a showcase for Jefferson books and journals, peer-reviewed scholarly publications, unique historical collections from the University archives, and teaching tools. The Jefferson Digital Commons allows researchers and interested readers anywhere in the world to learn about and keep up to date with Jefferson scholarship. This article has been accepted for inclusion in Department of Dermatology and Cutaneous Biology Faculty Papers by an authorized administrator of the Jefferson Digital Commons. For more information, please contact: JeffersonDigitalCommons@jefferson.edu. 


\title{
Outdated dermatologic drug samples and obligations to the patient
}

\author{
Jordan Wang, MBE, and Matthew Keller, MD \\ Pbiladelphia, Pennsylvania
}

\section{CASE SCENARIO}

A 37-year-old man with a slightly raised, red, scaly patch on his left arm is seen in the clinic of an academic teaching hospital by a young dermatologist. Following examination and biopsy, he is found to have squamous cell carcinoma in situ. The patient was recently laid off from work and had lost access to his health insurance. He is struggling to make ends meet for his family, so it would be difficult for him to cover any extraneous health-related expenses. Upon relaying this information to the dermatologist, the patient is provided with a full course of 5-fluorouracil (topical cream 5\%) from the clinic's sample cabinet. Later in the day, it is discovered that the same batch of drugs has been outdated for more than 4 months. Because the dermatologist was only recently hired, she worries that she will be severely reprimanded for her failure to inspect the expiry date.

\section{The dermatologist should:}

A. Not do anything because the drug sample was only recently outdated, and the risk for adverse outcomes may be considered to be relatively low.

B. Report the incident to a more senior dermatologist right away, and let that person ameliorate the situation.

C. Call the patient as soon as possible to warn him of possible dangers of using outdated drugs, and offer prompt exchange for a new sample.

D. Inform the patient of the potential risks associated with outdated drugs, promptly apologize, and make a sincere effort to regain the patient's trust.

\section{DISCUSSION}

Previous literature on medical errors has yet to focus on inadvertent outcomes in drug sampling with outdated drugs. Much more attention has been traditionally garnered by wrong site surgery and prescribing errors. Although these situations may result in more severe consequences, the increased frequency of outdated samples serves to bring this issue to the forefront. The future literature should further examine this type of medical error in an attempt to spread awareness.

Drug expiry dates are rigorously calculated based on determinants that account for the half-life of ingredients and expected conditions of

From the Department of Dermatology and Cutaneous Biology, Thomas Jefferson University, Philadelphia, Pennsylvania.

Funding sources: None.

Conflicts of interest: None declared.

Reprints not available from the authors.

Correspondence to: Matthew Keller, MD, Department of Dermatology and Cutaneous Biology, Thomas Jefferson storage. Outdated drugs may prove to have severely altered chemical stabilities and biological mechanisms of action. This can lead patients to believe that they are adhering to effective treatment when that might not be the case. Possible consequences include an adverse reaction or failure to achieve the desired therapeutic outcome. If the physician is the party responsible for providing outdated samples, then he or she should be accountable for notifying the patient, promptly apologizing, and rectifying the error regardless of the actual level of harm.

Commonly used dermatologic drugs are particularly sensitive to light, temperature, and moisture,

University Hospital, 833 Chestnut Street, Suite 740, Philadelphia, PA, 19107. E-mail: matthew.keller@jefferson.edu. J Am Acad Dermatol 2013;69:643-5. 0190-9622/\$36.00 (c) 2013 by the American Academy of Dermatology, Inc. http://dx.doi.org/10.1016/j.jaad.2013.04.034 
and such exposures can promote chemical processes of degradation and loss of activity. ${ }^{1}$ Improper storage also decreases the strength of dermatologic drugs. In the scenario described, adverse effects from the sample being outdated may be further compounded by potential storage conditions that have aided in the disruption of pharmacological stability. Fluorouracil topical cream is especially sensitive as evidenced by a recent manufacturing failure to guarantee standards of strength, quality, and purity due to inadequate conditions and inappropriate testing when establishing expiry dates. ${ }^{2}$ The dermatologist can assess neither the complete level of efficacy nor the total degree of risk associated with the drug sample in question.

To avoid the above scenario, dermatologists should have a system in place to regularly monitor the expiry dates of the drug samples in their inventory. Ideally, a readily accessible document should be created to record each of the individual dates, lot numbers, and prescribed patients. If drug sampling is to be continued, then dermatologists are obligated to keep detailed logs to protect their patients from any related harm. This process should be built to closely resemble that of pharmacy dispensing. Current drug sampling effectively bypasses the safety checkpoints that pharmacies are required to have in place to limit medication errors. Dermatologists should consider complete implementation of an electronic recordkeeping system that is updated concurrently with the intake and outtake of all samples. In addition, recommendations for suitable storage should be reviewed upon the receipt of all drug samples with the corresponding conditions appropriately maintained in the clinic. These specific tasks are essential to promoting proper patient protection and adherence to clinical safety guidelines.

Root cause analysis is a crucial part of our response when medical errors do unfortunately occur. Dermatologists are responsible for investigating why there was an error in patient care, how the event was allowed to occur in the current system, and what can be done to further prevent this error in the future. Regardless of how the medical error occurred, the dermatologist should assure the patient that all is being done to fix the system and may even expound on what changes are being implemented to prevent this from happening again.

Using the four basic principles of autonomy, beneficence, nonmaleficence, and justice alone as a diagnostic tool may lead to a failure on the physician's part to identify all of the applicable obligations owed to the patient. To maintain a healthy patient-physician relationship, the dermatologist in this case must fulfill additional moral obligations related to the medical error. The dermatologist has obligations to promptly apologize and to regain the patient's trust and confidence. These actions will help the patient understand that the dermatologist is still working in the patient's best interests regardless of the error that was made.

Although some physicians may not willingly admit that they have made a medical error, open expressions of regret and apologies are crucial primary steps to regaining patient trust. Attempts to make amends and to secure the patient's confidence are significant in rebuilding future rapport. Since 2001, the University of Michigan Health System has pioneered a policy of full disclosure for medical errors with offers of compensation to patients. The adoption of this program has decreased liability claims, patient lawsuits, resolution time, and associated costs. ${ }^{3}$ In response to this study, we believe that the cultures of medicine and health care should be even more accepting of physician practices of openly admitting mistakes and apologizing.

The disclosure of medical error is a cornerstone of contemporary medical professionalism. In 2001, The Joint Commission required medical disclosure by hospitals and their staff. Subsequently, seven states-Nevada, Florida, New Jersey, Pennsylvania, Oregon, Vermont, and California-have since mandated the disclosure of unanticipated health outcomes to patients. More than 30 states have also enacted laws to protect information conveyed during apologies and disclosures from being used in malpractice lawsuits. ${ }^{4}$

\section{ANALYSIS OF CASE SCENARIO}

In this case, option A is incorrect because it would be a gross mistake on the dermatologist's part to ignore the potential for harm to the patient. Patients place their health in the hands of their physicians, and this option would be an absolute breach of both trust and confidence inherent in the patient-physician relationship. Physicians should consistently strive to act in their patients' best interests, and any errors that compromise their well-being should be addressed.

Option B is an example of responsibility shifting between dermatologists and, therefore, is incorrect. This particular action should not be condoned in cases of medical error because patient crises often do not receive the immediate and proper attention that is warranted. Although it is certainly appropriate for an inexperienced 
physician to seek counsel from a more experienced colleague, it is ultimately the original physician's obligation to notify the patient and rectify the error. Physicians must be accountable for correcting their own mistakes, and they have the personal responsibility to undertake the healing of damaged patient-physician relationships.

Although option $\mathrm{C}$ warns the patient in a timely manner and offers an immediate replacement of the drug sample, nothing else is done on the dermatologist's part to further rectify the medical error. At first glance, this specious solution may appear to be correct because it is responsive to the patient's best interests and prevents any avoidable future harm. However, physicians must be aware of moral obligations that go beyond the concerns of beneficence and nonmaleficence relevant to this case, which makes this option only partially correct.
Option D not only notifies the patient of the associated risks and attempts to correct the mistake, but also goes further in fulfilling the physician's moral obligations to the patient in dealing with a medical error. Therefore, this option represents the best solution. The dermatologist shows concerns beyond the welfare of the patient by acknowledging features critical to the patient-physician relationship. The major burdens of maintaining a healthy patientphysician relationship continue to rest on the shoulders of the physician.

The efficacy of dermatologic drugs can be adversely affected by the length of time since manufacture as well as by improper storage conditions. If outdated drug samples have been provided to patients, it remains the ethical responsibility of the physician to correct this medical error and to repair the patient-physician relationship. In option $\mathrm{D}$, the dermatologist recognizes and fulfills her moral obligations to the patient.

\section{REFERENCES}

1. Langner MD, Maibach HI. Many common drugs in dermatology are light, temperature, or moisture-sensitive. Skin Therapy Lett 2009;14:3-5.

2. Food and Drug Administration. Warning letter: Legacy Pharmaceuticals International [Internet]. 2008 [updated 2009 Jul 8; cited 2013 Apr 7]. Available from: http://www.fda.gov/

ICECI/EnforcementActions/WarningLetters/2008/ucm 1048312. htm.

3. Kachalia A, Kaufman SR, Boothman R, Anderson S, Welch K, Saint S, et al. Liability claims and costs before and after implementation of a medical error disclosure program. Ann Intern Med 2010;153:213-21.

4. Gallagher TH, Studdert D, Levinson W. Disclosing harmful medical errors to patients. N Engl J Med 2007;356:2713-9. 